\title{
ASPECTS OF STUDYING EMOTIONS IN LINGUISTICS
}

\author{
Liliya R. Sakaeva ${ }^{1}$ \\ Marat A. Yahin ${ }^{2}$
}

Gulfiya S. Mullagayanova ${ }^{3}$

\begin{abstract}
The study of emotions is primarily related to psychology, although other sciences also pay enough attention to this problem. The authors of

related to the manifestation of emotionality in the language. So, this research paper deals with the aspects of studying emotions in linguistics.
\end{abstract} the article make a brief review of the researches carried out by linguists in the sphere of emotions. The readers are suggested a survey describing a number of key Russian and Kazakhstani scientists involved into studying emotions. The popularity of studying emotional features of lexemes and texts has not diminished over the years. On the contrary the linguists as well as psychologists and scientist of other fields of science devote a lot of time and efforts to the issues related to emotions. There is a considerable number of researches devoted to the study of the verbalconceptual set of emotions in modern linguistics, but the science of language is not yet ready to answer all the questions
Keywords: Language, speech, semantic, explication, linguistic world view, Emotions, perception.

\section{Introduction}

In the field of cognitive linguistics the well-known works are those belonging to Y.L. Goncharova, E.Y. Myagkova, O.O. Budyanskaya, etc.; Z. Kovescheş, V.I. Shakhovsky, S.V. Zaykina, A. Zaliznyak and others deal with emotions within the frames of cultural linguistics. So, there are a lot of cross-disciplinary researches such as those made within linguistics and psychology. Psycholinguistics is a science, the subject of which is the

\footnotetext{
${ }^{1}$ Kazan Federal University, Institute of International Relations, History and Oriental

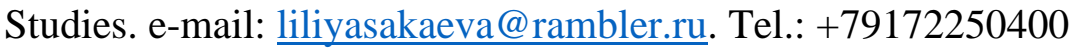

${ }^{2}$ Kazan Federal University, Institute of International Relations, History and Oriental Studies.

${ }^{3}$ Kazan National Research Technical University named after A.N. Tupolev-KAI, Kazan, Russian Federation.
} 
relationship between the language system and the language ability. Psycholinguistics studies the processes in which the intentions of the speakers are transformed into the signals of the code accepted in the given culture and these signals are transformed into the interpretations of the listeners. The subject of psycholinguistics is speech activity as a whole and conformity to the principles of its complex modeling. A.A. Leontiev makes quite clear distinctions of this science framework; in his work "Psycholinguistics" he notes that the speech mechanism of the listener and the speaker is not fundamentally different. The author emphasizes that "everything comes down to simple accumulation, mechanical sorting and repetition of what was heard". At the same time he distinguishes the roles of scientists in two different fields: "A linguist deals with what to accumulate and a psychologist with how to accumulate (information)" $[1,22]$.

\section{Methods}

We offer to consider a brief overview of the aspects of studying emotions in linguistics together with the methods used for this purpose. D. Romanov examines psycholinguistic grounds of emotional identification, that is, particular combinations of variants of emotional states names. Lexical means, denoting emotions in the Russian language, are systematized by him on the basis of twenty fundamental emotional modalities, which include the following: surprise, interest, determination, love, anxiety, fear, grief, suffering, shame, shyness, guilt, contempt, disdain, anger, rage, disgust, loathing, happiness, joy and pleasure (udivleniye, interes, reshitelnost, lyubov, trevoga, strakh, gore, stradaniye, styd, zastenchivost, vina, prezreniye, prenebrezheniye, gnev, yarost, otvrashcheniye, omerzeniye, schastye, radost i udovolstviye).

The researcher notes two significant problems encountered in studying various aspects of emotions both in linguistics and other sciences. A lot of scientific research has been devoted to the model attribution of emotionality. The start to the systematic study of emotive models of the state and their inventory was given in the works of S.N. Tseitlin, L.I. Vasilievsky, A.G. Kondiushenko. Another issue connected with the topic is identification of emotional states; here one can note a lot of white spots that are waiting for their researcher, according to D.A. Romanov. 
Partially, this problem is revealed by the author, where he makes an attempt to distribute the dominant emotions and their varieties into groups by lexical meaning. The empirical part of the research is based on samples of emotions names taken from dictionaries of synonyms and on the results of the conducted cluster analysis. As a result, the author comes to several conclusions. First, it was found that the naive emotional world view is symmetrical to the scientific, which means that people when identifying emotions do not realize the components of modality factor characteristics to the full extent, but subconsciously use them in groupings and classifications of emotions. Secondly, emotional identification can be applied to any direct lexical characteristics (names) of emotions, such as language lexemes-synonyms of fundamental emotions or metaphorical names of modalities, or authorial figurative definitions or emotional nonce formations, etc. Thus, D.A. Romanov confirms that emotion can naturally be called in different ways, having thus a basic form, or the basic modality.

\section{Results and discussion}

Despite the fact that a lot of attempts have been made to systematize the description of language units expressing or naming emotions, the researchers still interpret the very concept of emotions in different ways and put different meanings into it. This fact can be explained both by the variety of approaches in the study of this phenomenon and by the complexity and inconsistency of the phenomenon itself. Emotions are an integral part of a person and his speech activity. Perception of various kinds of information by a person is individual due to the personal characteristics. Emotions manifestation is also specific for every speaker: some people are more and some are less emotional. This explains why psychologists distinguish four kinds of temperament, which were once designated by Hippocrates. So, for example, a sanguine person is characterized by quickness, rapid excitability and easy changeability of emotions. A phlegmatic is described as a slow person, possessing calm temperament with inherent weak sense of outwardness. As for the melancholic, this psychological type is characterized by increased impressionability and a relatively insignificant external 
manifestation of senses. People with this temperament tend to be depressed, with frequent moods of sadness and depression. A choleric is described as a type possessing quickness of action, strong, fast-paced feelings, which are vividly reflected in speech, gestures and facial expressions. Thus, people are divided into 4 types of temperament, although it should be noted that mixed types of temperament are more common for people. Characterizing personality by temperament S.L. Rubinshtein points out that the activities of different natures directly depend on the mental state and on how they experience the attitude to the surrounding reality. But it is also known that different native speakers can cause various reactions, including speech actions in one and the same situation. Thus, despite the existence of a common linguistic world view this happens due to the individual knowledge background and experience as well as owing to the situation and circumstances. Comparing the people of different origins, here, in addition to individual characteristics, also arises the question of variety in perception due to the differences in linguistic world view.

It is important to note that the meaning the communicants put into the linguistic sign is mobile: "... the sign can have different meanings for different individuals, as well as for one individual, but at different times" $[3,172]$. This is also confirmed by V.I. Shakhovsky in his work "On the Role of Emotions in Speech" (O Roli Emotsiy v Rechi), where it is noted that "the same thing, the same situation, the same chain of events in the same individual at different times can cause different and sometimes even contradictory emotions, not to mention different individuals" $[4,111]$. Thus, the "choice" of emotion in a particular situation is conditioned by the psyche of a particular individual, national and cultural features, specific situation, a proposition, disposition, and other factors.

V.I. Shakhovskiy introduces a specific component of the word meaning i.e. emotive. This component, in his opinion, is the result of reflection of emotions in the word in the process of their verbalization and semantization. Being socially generalized, this component serves for the individual expression of emotional appraisal of the world objects, the implementation of which occurs in emotional situations of communication through the emotional type of speech acts. In emotionology it is 
common to distinguish between: nominative (naming), descriptive (describing) and expressing (actually emotive) units. This classification is studied in details and described by V.I. Shakhovskiy [4].

L.G. Babenko studies the systemic linguistic and speech capabilities of denoting emotions in the Russian language. The researcher represents typological classifications of emotive vocabulary in her works. The author also turns to the identification of the emotive semes of different ranks in the semantic structure of the word (intraverbal paradigmatics) which is the basis for describing the structure of the field of emotions in the Russian language (interverbal paradigmatics). L.G. Babenko singles out emotive vocabulary corpora in the Russian language, which can belong to either positive or negative ones. In contrast to V.I. Shakhovskoy L.G. Babenko understands the emotional value in a different way: this is the meaning (seme) in the systemic structure of which there is a seme of emotivity of a particular rank. In other words, it can be designated as a value in which emotive meanings are represented in a certain way $[5,32]$.
Russian scientist Y.L.

Goncharova conducted a cognitive study of emotions word-names in the Russian language. She attempted to analyze both semantic and pragmatic properties of emotions names. Due to the fact that there was revealed a higher degree of synonymy in comparison with antonymy, the author took the synonymous series of nouns denoting positive and negative emotions as the units of analysis. Also, Y.L. Goncharova drew attention to the evaluation function of emotions. It seems interesting to us to conclude that denominations of negative emotions can be used to express both negative and positive assessments.

In addition to the nouns representing the emotions, the researchers were also interested in other parts of speech. Here it is necessary to pay attention to the works of S.S. Polezhaev, M.B. Amalbekova, L.M. Vasilev, M. Orazov and others who considered verbs in their scientific studies. As for the researches of such grammatical classes as adjectives and adverbs, a small percentage of covering can be noted here. This makes it possible to deepen the study of this issue in linguistics. 
Having considered the range of problems studied by linguists in the aspect of modern linguistics, we can distinguish four types of emotive units:

- vocabulary used for naming feelings;

$$
\text { - vocabulary used for }
$$

expressing feelings;

- vocabulary characterizing the emotional state undergoing; and

- vocabulary conveying the external manifestation of emotions.

Thus, any of the above lexical units can claim the status of an emotive unit.

The emotions are frequently being researched within the framework of cognitive aspect. Some of A. Wierzbicka's studies are devoted to the development of cognitive scenarios of emotions. Such scenarios are identified through lexical universals, which allow us to explore human emotions from a universal point of view, independent of a particular language $[6,12] . \quad A$. Wierzbicka primarily uses cognitive scripts to describe various emotional concepts. N.D. Arutyunova, T.V. Bulygina, S.G. Vorkachev, N.V. Dorofeeva, S.V. Zaikin and some other linguists deal with studying certain emotional concepts. Today the linguistic cognitive approach provides an opportunity to view linguistic units as a means of cognition of human consciousness, which in turn allows the researchers to study the mechanisms of understanding emotional concepts from the point of view of their perception in terms of the representatives of different cultures.

Thus, to identify the specific features of ethnical cultural aspect of emotions, the researchers turned to the study of emotive concepts in various linguistic world views. Concept is one of major units of culture in the mental world of a man as it is determined by culture and objectified in the language. Belonging to one or another culture predetermines the level of emotionality and its intensity. A. Wierzbicka, for example, points to a greater degree of emotional expression in Russian compared to the English language. As for the study of emotional concepts, the analysis is intended to show their extremely complex conceptual structure and, consequently, their significance in the mentality of a person, which is undoubtedly reflected in the speech of native speakers. So, this field of study has a lot to do and still waits for a research. 
O.O. Budyanskaya and E.Y. Myagkov considered the means of describing emotions in the English and Russian languages using the examples of fear (strakh) concepts. As a result, the researchers revealed the features specific to perception of fear through idiomatic expressions. The concept of "longing" (toska) was considered by Y.L. Goncharova on the material of the Russian language in comparison with the equivalents used in the texts translated into English. She found out new pragmatic components in the semantic content of the given name that were not fixed in lexicographic sources. Linguists have also paid attention to such emotional concepts as "anger" (gnev), “joy" (radost'), "happiness" (schastye), etc. Thus, the term "emotional concept" became common for linguists, although the initial positions that served as the basis for distinguishing the abovementioned concept is not absolutely indisputable. One of the allegations being questioned is that the emotional concept is based on an emotional notion. So, taking emotional notion as a basis, N.A. Krasavsky singles out emotional concepts. However, any concept can include both intellectual or rational component and emotional or affective.
Kazakhstani linguists also did not ignore the relevant issues of studying emotions in the language. For example, Z.Kh. Ibadildina studied emotive vocabulary in the perspective of comparing Kazakh and Russian. M.B. Amalbekova focused on the problems of describing the verbs that denote emotions and their causation. In the study, the author notes the ability of emotions to be graded or ungraded. G. Kazhigalieva dealt with the emotive words in the lexical and word-building system of the modern Russian language, where a special role was assigned to the semantic field of "anger". In her research, the author notes semantic derivation as the most productive way of implementing the emotional potential of the word, and also allocates the semantic field of "anger" emotive words to the part of speech tagging structure. Thus, it is clear that linguists from different countries have been dealing with the issues connected with emotions, but, nevertheless, there still remains a wide range of problems that require the study.

\section{Summary}


A brief review of the history of studying emotions in linguistics leads us to the following conclusions. At present, the linguistic science has accumulated a large amount of experience of studying emotions in the language. Different linguistic researchers address this issue from the point of their views and interests, which, of course, has both advantages and disadvantages. As for the first, they are obvious and the explanation can be limited only by the fact that when studying any phenomenon, whether it is linguistic or belonging to any other science, approaches from different points of view are needed, as well as studying at different levels. So, in order to obtain a complete vision of the phenomenon under research, it is necessary to organize studies both horizontally, in the aspects of different disciplines related to the subject matter, and vertically, which in this case means exploring from different points of view of a single science. If we talk about the disadvantages, first of all it is necessary to note a different vision of the same problem, which contributes to the emergence of contradictions. Another drawback of studying emotions from different sides is a different understanding of the same phenomenon, that is, the sparseness of terms.

\section{Conclusions}

Some researchers of emotions consider it impossible to accurately identify emotions through speech notions; the doubts in precise identification of emotion can be caused by different factors. For example, some emotions physically cannot be identified precisely, that is, there are situations when it is profitable for the speaker to demonstrate, or "to play" the feeling that is not really experienced. Another reason for the incorrect identification of emotions is inability of the listener to accurately determine it by virtue of inattention or due to lack of acquaintance with the speaker. Thus, there can be a lot of reasons for the incorrect recognition of emotions.

This phenomenon is mentioned by V.I. Shakhovskiy who paid attention to the facts of verbal concealment or filtering of true emotions. Thus, N.V. Vitt, in one of his works on emotions, quotes J. Mandler, where the latter states the following: "If we want to find out what feelings people are experiencing, the only way to find out is to ask them: it is difficult to find nonverbal ways of 
finding out emotional experiences" $[7$, 96].

So, this work deals with some studies of emotions in different aspects based on Russian, English and Kazakh languages. We have tried to cover the overall range of problems studied by the above mentioned authors. But at the present time there is still a wide range of issues related to emotions that need to be paid attention to and this article may help to get closer to the unresolved problems of emotion studies.

\section{Acknowledgements}

The work is performed according to the Russian Government Program of Competitive Growth of Kazan Federal University.

\section{Bibliography}

Leontyev, A.A. (1967). Psikholingvistika, Leningrad, Izd. «Nauka», 118 s.

Ackoff, Russell I. and F. E. Emery. On Purposeful Systems. Chicago: AldineAtherton, 1974, P. 172.
Shakhovskiy, V. I. (1991). O roli emotsiy v rechi, Voprosy psikhologii, 6, S. 111116.

Shakhovskiy, V.I. (1987). Kategorizatsiya emotsiy v leksiko-semanticheskoy sisteme yazyka, Voronezh, S. 192.

Babenko, L.G. (1990). Russkaya emotivnaya leksika kak funktsionalnaya sistema, dis. d.filol.nauk, Sverdlovsk, 611 S.

Wierzbicka, A. (1999). Emotional Universals // Language Design, \# 2, P. 23 69.

Vitt, N.V. (1991). Lichnostnosituatsionnaya oposredovannost vyrazheniya i raspoznavaniya emotsiy $\mathrm{v}$ rechi //Voprosy psikhologii, № 1, S. 95107.

Leech, G.N. (1983). Principles of Pragmatics, London: Longman.

Yahin, M.A., Sakaeva, L.R., Mikhailovna, B.O. (2016). The comparative analysis of anthropocentric phraseological units in Russian, English and Tatar [10] Languages // Social Sciences 11(16), P. 4048-4052 
Uryson, E.V. (2003). Problems of the linguistic worldview study: Analogy in semantics. Moscow: The Slavic languages.

Spirina, T.S., Sakaeva, L.R. (2015). Structural Models of phraseological units characterizing power in the English, German and Russian languages // Asian Social Science, 11(7), P. 145-151.

Takhtarova S., Communicative category of politeness in German and Russian linguistic culture//Mediterranean Journal of Social Sciences. - 2015. - Vol.6, Is.3. P.497-502. 